\title{
DO DISTURBANCES ALTER COMPETITIVE HIERARCHIES? MECHANISMS OF CHANGE FOLLOWING GAP CREATION
}

\author{
Katharine Nash Suding ${ }^{1}$ And Deborah Goldberg \\ Department of Biology, University of Michigan, Ann Arbor, Michigan 48109-1048 USA
}

\begin{abstract}
Many studies have documented that patterns of species composition change after gap creation, but few have addressed the processes responsible for this change. The idea of competitive reduction, that disturbance removes biomass, reducing competitive intensity and allowing competitively inferior fugitive species to colonize, has been widely accepted but rarely tested. We suggest an alternative hypothesis, competitive change, in which changes associated with disturbance may act to alter the competitive hierarchy. Under these changed conditions, species characteristic of gaps may be competitively superior to species characteristic of undisturbed matrix areas.

We quantified competitive response ability for survival and relative growth for three target species (Andropogon gerardii, a matrix grass; Coreopsis tripteris, a matrix forb; and Ratibida pinnata, a forb characteristic of gaps) in undisturbed matrix vegetation and in soil mound disturbances in a northern Ohio prairie community. For survival, a weak competitive hierarchy developed following gap creation. In contrast, for relative growth, gap creation shifted a distinct competitive hierarchy to conditions of competitive equivalence. The competitive rankings for survival in gaps were opposite those for growth in matrix conditions, with Andropogon being superior in terms of survival and Coreopsis superior in terms of growth.

Then, in a factorial design, we teased apart the effects of neighborhood (biomass reduction, size structure, neighbor identity) and abiotic soil changes (mound formation) associated with soil disturbance on these competitive interactions. Abiotic changes associated with mound formation, rather than neighborhood changes, were responsible for the development of the survival hierarchy and the loss of the growth hierarchy following gap creation. When hierarchies formed, matrix species were competitively superior to gap species, supporting the idea of competitive reduction. However, no one matrix species was consistently competitively superior, and under some conditions species were competitive equivalents, partially supporting the idea of competitive change. When disturbance creates conditions of physical stress, as in this case, trade-offs between growth and survival hierarchies may be important determinants of species response.
\end{abstract}

Key words: abiotic stress; Andropogon gerardii; competitive hierarchy; Coreopsis tripteris; gap creation; growth and survival hierarchies; interaction intensity; prairie ecology; Ratibida pinnata; size structure; soil disturbance.

\section{INTRODUCTION}

It is clear that disturbance can alter plant community composition and diversity (see reviews by Pickett and White [1985], Petraitis et al. [1989]), but the mechanisms responsible for the changes have rarely been tested. The most common explanation for these changes is competitive reduction: disturbance reduces competitive intensity by either removing the competitively dominant species or simply reducing density overall, allowing competitively inferior "fugitive" species to persist because they are better able to rapidly colonize gaps (Levins and Culver 1971, Horn and MacArthur

Manuscript received 19 May 2000; revised 28 July 2000; accepted 5 September 2000.

${ }^{1}$ Current address: University of Colorado, Institute of Arctic and Alpine Research and Department of Environmental, Organismic, and Population Biology, Campus Box 450, Boulder, Colorado 80309-0450 USA.

E-mail: suding@colorado.edu
1972, Peart and Foin 1985, Belsky 1986b, Hobbs and Hobbs 1987, Hobbs and Mooney 1991, Tilman and Pacala 1993, Tilman 1994; Fig. 1A). Similarly, some commonly used definitions of disturbance revolve around the removal of biomass decreasing overall competitive intensity; for instance, Tilman (1988) simulates disturbance in his models by varying the loss rates of biomass, and Grime (1979) defines disturbance as "a mechanism which limits plant biomass by causing its partial or total destruction." Consistent with this explanation, competitive intensity has been found to decrease with disturbance intensity (Wilson and Keddy 1986, Campbell and Grime 1992, Turkington et al. 1993, but see Wilson and Shay 1990) and disturbed areas generally do have lower levels of neighbor biomass (e.g., Platt and Weis 1977, Hobbs and Mooney 1985).

However, abundant evidence suggests that reduced competition may not be entirely sufficient to explain 


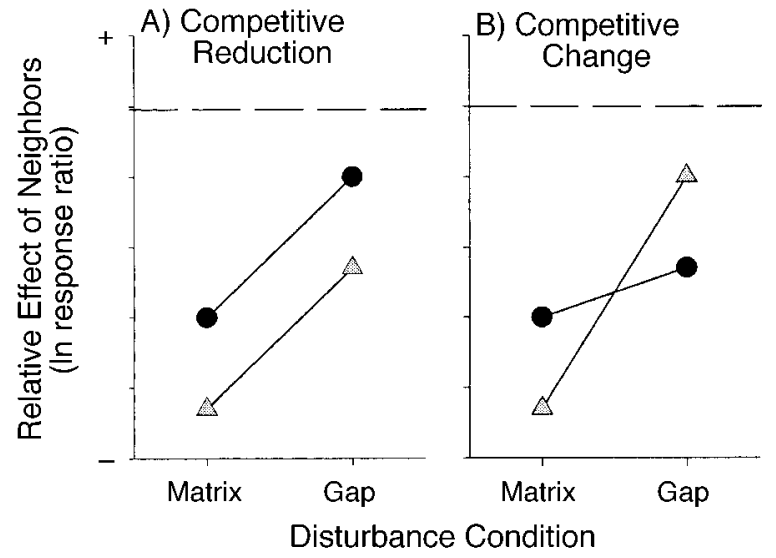

FIG. 1. Predictions of relative competitive abilities in matrix vs. gap areas for matrix species (solid circles; characteristic of undisturbed habitats) and gap species (triangles; characteristic of disturbed habitats): (A) competitive reduction and (B) competitive change. In both scenarios, we illustrate competitive interactions; it would also be possible to find situations where neighbors are facilitative, or where competition shifts to slight facilitation (or vice versa). We also assume that overall competitive intensity decreases in gap conditions in all scenarios

changes in plant community composition following a disturbance. In addition to reducing density or biomass overall, disturbances can change both the abiotic soil environment (Vitousek and Melillo 1979, Chazdon and Fletcher 1984, Allen 1985) and neighborhood characteristics such as composition and size structure (Platt and Weis 1977, Gibson 1989, Martinsen et al. 1990, Umbanhowar 1992, McIntyre et al. 1995). Empirically based definitions of disturbance (e.g., Pickett and White 1985, Petraitis et al. 1989, Pickett et al. 1989) recognize the importance of these other changes associated with a disturbance. Moreover, research has addressed how individual plants respond to many of these changes (Cood and Lyons 1983, Coffin and Lauenroth 1988) and how these responses differ among species (Hobbs and Mooney 1985, Belsky 1986a, Hobbs and Atkins 1988, Coffin and Lauenroth 1989, Umbanhowar 1992, McIntyre et al. 1995). However, the potential effects of these changes on competitive interactions have been rarely addressed (see Rabinowitz and Rapp [1985a], Wilson and Tilman [1995] for exceptions); plants are assumed to respond simply to the reduction of neighbor biomass and subsequent decrease in the intensity of competition.

If disturbance only acted to reduce competition, we would expect the intensity of competition to decrease but the relative competitive rankings to be maintained (Fig. 1A). In this case, disturbance may modify species associations simply by permitting a shift to species that are less competitive but are superior colonizers (Collins and Glenn 1991). However, interactions have been found to occur within gaps (Platt and Weis 1985, Martinsen et al. 1990, McConnaughay and Bazzaz 1990,
Umbanhowar 1995, but see Rabinowitz and Rapp $1985 b$ ). It might be the effect of these interactions, instead of or in addition to colonization limitation (Aguilera and Lauenroth 1995, Brewer et al. 1998), that determines species composition. Disturbance could act as a strong selective force on species traits (Harper 1977, Denslow 1980, Miao and Bazzaz 1990), allowing particular species to tolerate or even take advantage of specific environmental changes due to disturbance (Martinsen et al. 1990, McIntyre et al. 1995). Many models of community structure assume tradeoffs among traits, which result in trade-offs in competitive ability in different environments (Tilman 1988, Smith and Huston 1989); in the same vein, traits that confer competitive ability in undisturbed matrix conditions may not be the same ones advantageous in gap conditions.

In this paper we describe and test an alternative to competitive reduction to explain patterns of species compositional change due to disturbance (Fig. 1B). The competitive change hypothesis predicts that the competitive hierarchy may shift in gap compared to nongap conditions, influencing the nature, not just the intensity, of competitive interactions. We suggest that species that are associated with disturbances may outcompete matrix species under disturbed conditions.

Both neighborhood and abiotic mechanisms exist that could potentially cause shifts in competitive hierarchies in disturbed relative to undisturbed areas (Fig. 2). First, the reduction of neighbor biomass, in addition to altering overall competitive intensity, could alter competitive rankings if species respond differentially to decreases in neighbor biomass such that competitive hierarchies change at low relative to high biomass. Second, disturbance generally changes the size structure of the neighboring vegetation. In many disturbances, colonists will interact largely with other seedling colonists or other resprouts (size-even interactions), while in undisturbed vegetation seedling colonists mostly interact with much larger adults (size-uneven interactions) (e.g., Platt and Weis 1985, Umbanhowar 1995). Because the ability to preempt resources by fast growth is expected to be important under size-even interactions, while the ability to tolerate low resource levels (often associated with low growth [Chapin 1980, 1991, Lambert and Poorter 1992]) is expected to be important under size-uneven interactions (Goldberg 1990), a change in size structure could alter competitive hierarchies. While size structure has been largely confounded with biomass in experimental work to date, some evidence indicates it can change competitive rankings (Platt and Weis 1985, Bush and Van Auken 1995). Third, species composition usually changes in an area after it has been disturbed (Belsky 1992, McClure and Lee 1993, McIntyre and Lavorel 1994). To the extent that interactions are specific to species (or to functional groups), the change in strength of neighbor competitive effects may change the response of 


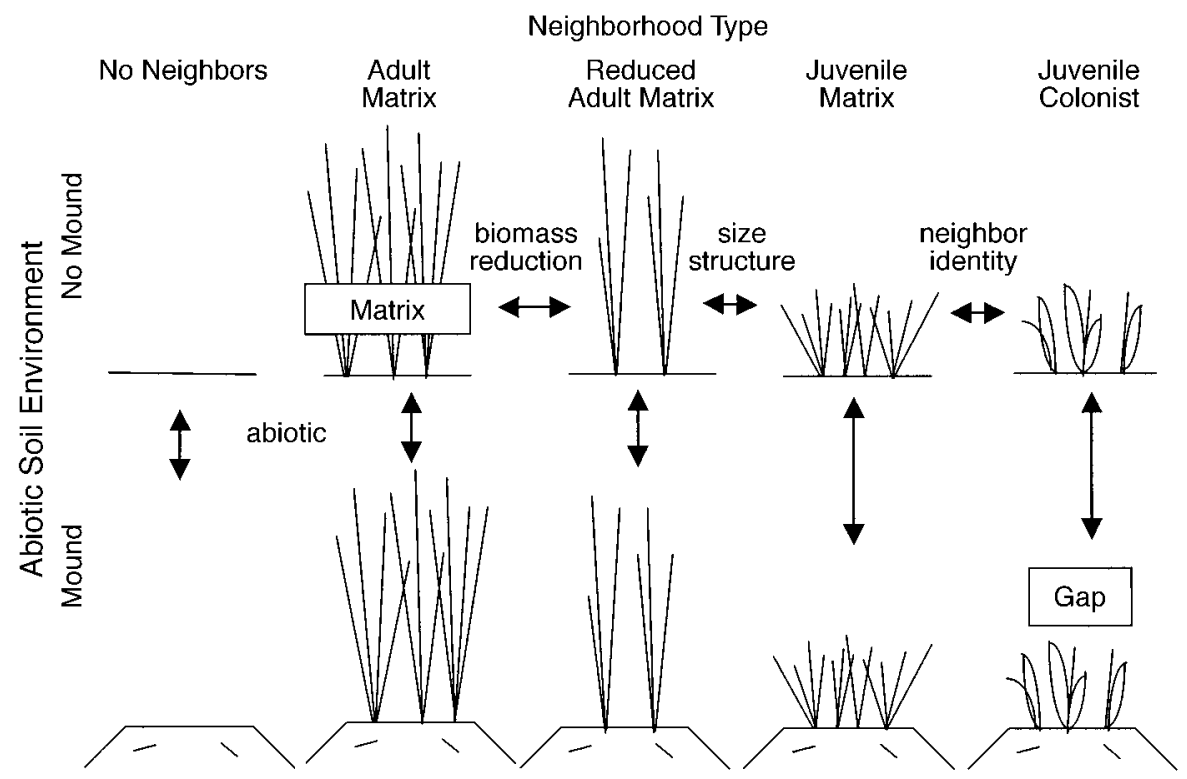

FIG. 2. We established plots that consisted of all possible combinations of two abiotic soil treatments (no mound, mound) and five neighborhood treatments (no neighbors, adult matrix neighbors, reduced adult matrix neighbors, juvenile matrix neighbors, and juvenile colonist neighbors). Competitive interactions were assessed by comparing target performance in the absence and in the presence of neighbors (each of the four neighborhood types) in both abiotic soil environments (no mound and mound). We assessed the overall gap effect by comparing competitive ability in matrix conditions (adult matrix, no mound) to gap conditions (juvenile colonist, mound). We then break that overall effect into more mechanistic components, indicated by the arrows (biomass, size structure, neighbor identity, abiotic alteration). An eleventh treatment, a nonmanipulated control (adult matrix without transplanting) is not shown.

other colonists (Wilson and Tilman 1995, Peltzer et al. 1998). Fourth, in addition to changing neighborhood characteristics, many types of disturbance also change the abiotic soil environment (Vitousek and Melillo 1979, Chazdon and Fletcher 1984, Allen 1985, Nakashizuka 1989). These alterations, independent of changes in neighborhood conditions, could shift competitive hierarchies if some species are better competitors in different physical environments than others (see Goldberg [1996] for a review).

We have two goals. First, we examine competition intensity and competitive hierarchies under both matrix and gap conditions to distinguish between the general hypotheses of competitive reduction and competitive change (Fig. 1). While these two hypotheses are not incompatible, they do differ in their predictions concerning whether competitive hierarchies change following disturbance and which type of species are competitively superior in gap conditions. Second, because many factors change simultaneously in an actual disturbance, we tease apart the influence of four factors (biomass, size structure, species composition, and abiotic soil environment) to determine what changes are responsible for any overall effect on competitive rankings (Fig. 2).

We examine competitive response, the ability to tolerate or avoid suppression of neighbors (Jacquard 1968, Goldberg and Werner 1983), comparing the hierarchies formed for juveniles of prairie species characteristic of different disturbance regimes. Because it is likely that the most appropriate measure of overall individual "success" may differ between environments and tradeoffs may exist between different measures of performance, we quantify the effect of neighbors on both individual growth and survival.

\section{Methods}

\section{Study area and plant species}

We worked in a prairie at the Resthaven Wildlife Area (Ohio Department of Natural Resources) near Castalia, Ohio, $\sim 8 \mathrm{~km}$ south of Lake Erie. This prairie is a 100 -acre (40.47-ha) remnant of the prairie peninsula, part of the easternmost extension of the tallgrass prairie (Ramey and Troutman 1976). Within the prairie, species that grow on small $(10-70 \mathrm{~cm}$ diameter) soil mounds created by small animals tend to differ from those that characterize the matrix prairie (Suding 1999).

Juveniles of three species were used as targets: a matrix grass, Andropogon gerardii Vitman (big bluestem: Poaceae); a matrix forb, Coreopsis tripteris L. (tall Coreopsis: Asteraceae); and a gap forb, Ratibida pinnata Vent. (gray-headed coneflower: Asteraceae). We originally included a fourth species, the gap grass, Phleum pratense L. (Timothy grass: Poaceae) so that we could have species represent all possible combinations of growth form (grass or forb) and abundance 
pattern (matrix or gap). Unfortunately, Phleum experienced extreme mortality under all treatment conditions (only 12 of 264 target individuals survived the first growing season) due to meadow vole herbivory. It therefore could not be included in the analyses and is not discussed further.

\section{Experimental design}

The factorial experiment was a randomized block design, with all combinations of the three target species and five neighborhood treatments and two abiotic environment treatments that simulated different aspects of soil mound disturbances in the prairie. We refer to "gap conditions" as the combination of all neighborhood and abiotic soil changes that occur following a disturbance (as would be found naturally) and "mound formation" as just the abiotic soil alterations following a disturbance (manipulated independently of neighborhood changes in our experimental design; see Methods: Experimental design: Abiotic soil environment).

The treatments were replicated in each of eight blocks, for a total of 240 plots. In addition, a transplant control plot was planted for each species in each block (24 additional plots). Experimental plots were $0.5 \mathrm{~m}$ in diameter with a $0.3-\mathrm{m}$ buffer zone of clipped vegetation around the edge. Plots were spaced at $2-\mathrm{m}$ intervals. Neighborhood and abiotic treatments were implemented between 3 May and 26 May 1997.

Biotic neighborhood treatments.-To isolate the effect of each of the three neighborhood components of gap creation (biomass, size structure, neighbor identity) from each other, we established four neighborhood treatments: adult matrix (AM), reduced adult matrix (RAM), reduced juvenile matrix (RJM), and reduced juvenile colonist (RJC). The "reduced" neighborhoods had biomass reduced to $10 \%$ of typical matrix vegetation; this is approximately the amount typical of firstyear gaps in this prairie (Suding 1999). The "juvenile" neighbors were of similar size to the target seedlings (size-even interactions), while "adult" neighbors were much larger than the seedling targets (size-uneven interactions). "Matrix" and "colonist" refer to species typical of matrix vegetation or gap vegetation, respectively. To assess competitive ability in all neighborhoods (see Methods: Target response competitive ability, below), we also established a no-neighbor treatment (NN). Specific neighborhood comparisons measured the effect of each neighborhood component of gap creation (Fig. 2): comparison of the adult matrix and reduced adult matrix neighborhoods (AM vs. RAM) yielded the effect of biomass reduction; comparison of the reduced adult matrix and juvenile matrix (RAM vs. JM) yielded the effect of size structure; and comparison of the juvenile matrix and juvenile colonist (JM vs. JC) yielded the effect of neighbor identity.

In the reduced adult biomass plots (RAM), we kept one in every ten individuals of every species to maintain relative abundances but reduce biomass to $\sim 10 \%$ of that of natural matrix vegetation. Neighbors that were ultimately to be kept in these plots were first taken out of the plots with a bulber (which removes a core $6 \mathrm{~cm}$ in diameter and $15 \mathrm{~cm}$ deep). The herbicide glyphosate (Roundup, Monsanto, St. Louis, Missouri, USA) was applied with a sponge to the remaining plants, and then the neighbors to be kept were transplanted back into the plots. All standing litter (including the dead, herbicided plants) was clipped at the ground surface and removed. We marked the original neighbors with colored wire so as not to confuse them with new colonists, and each week weeded the colonists. All individuals in adult matrix neighborhoods (AM) were also removed with a bulber and replanted to account for effects of transplanting of neighbors. These plots were not weeded. To assess the effect of transplantation, we also established plots in matrix adult vegetation where we did not remove and replant neighbors. We found no effects of neighbor transplantation on either target response (for all dependent variables, $P>0.45)$ or neighbor growth $\left(F_{1,30}=0.02, P\right.$ $=0.89$ ). In no-neighbor plots $(\mathrm{NN})$, all neighbors were killed with herbicide and removed by clipping with little disruption of the soil surface.

To achieve a juvenile neighborhood of matrix species (RJM), we removed all existing vegetation (by herbiciding and clipping as in the no-neighbor treatment above) and then transplanted seedlings of the matrix species as neighbors. The seedling neighbors were grown at the Mathaei Botanical Gardens (Ann Arbor, Michigan, USA), along with the target individuals, from seeds collected at the prairie the previous autumn. We planted the seedlings in the appropriate numbers and species relative abundances to have the plot contain about the same level of neighbor biomass and species composition as the uneven-sized reduced-adult matrix neighborhood described above (RAM).

To obtain a neighborhood of colonist species (reduced juvenile neighborhood of colonist species, RJC), species were allowed to colonize the plots naturally. These plots were not weeded. To equalize the temporal differences in biomass accumulation between this treatment and the juvenile neighborhood of matrix species (RJM, above), we allowed 3 wk for colonists to establish on the bare plots before planting the matrix seedlings.

Abiotic soil environment.-All the neighborhoods described above were planted both on and off mounds (Fig. 2). We simulated mounds similar to those formed by small mammals by extracting existing plants with a bulber, turning over the soil to a depth of $15 \mathrm{~cm}$, removing the remaining roots and crowns, and then loosening the soil (after Collins 1989). In neighborhoods where some of the original plants were to be kept (i.e., in AM and RAM neighborhoods), we replanted some or all of the removed plants to the appropriate treatment levels as described above. After one 
growing season, mounds averaged $44 \mathrm{~cm}$ in diameter and $12 \mathrm{~cm}$ in height.

\section{Target planting and monitoring}

On 5 May 1997, seeds of the three target species were sown in flats in a greenhouse at the Mathaei Botanical Gardens. On 28 May 1997, three juvenile individuals of the same species were transplanted, $12 \mathrm{~cm}$ apart, into the center of each plot. The initial number of leaves, basal diameter, and height of the planted targets were measured and representative seedlings that were not transplanted into plots were dried to constant mass and weighed. Regressions of aboveground biomass of these weighed seedlings on the nondestructive size measures were used to estimate the initial biomass of the planted targets. On 16-18 September 1997, the number of leaves, basal diameter, and height of all target plants were measured again. In plots where all three target individuals survived to the end of the first growing season, the aboveground portion of one target plant was harvested (the "interim harvest"), dried to constant mass, and weighed. As for initial biomass estimations, regressions of aboveground biomass of the harvested targets on the size measures were used to estimate the 1st-yr interim biomass of the unharvested individuals. On 19-20 September 1998, the remaining surviving targets in each plot were harvested for aboveand belowground biomass, dried to a constant mass, and weighed.

Survival was calculated within each year for each plot as the proportion of target individuals alive in September relative to those alive in May. All plots started with three targets in the first growing season and up to two (because one target was harvested if all three survived; see paragraph above) at the start of the second. Relative growth in the first year was calculated assuming arithmetic growth as the difference between the aboveground biomass of the target at the interim harvest and at initial planting, divided by the initial target biomass. Relative growth in the second year was calculated similarly, as the difference between the aboveground biomass at the final harvest and interim harvest, divided by the target biomass at the interim harvest. Using relative rather than absolute growth simplifies comparisons among the three species, which differ in absolute size (see Results: Target performance in the absence of interactions). We analyzed both mean target relative growth and the sum of the relative growth of all surviving targets in each plot but results were similar (Suding 1999), indicating that the three target individuals did not influence each others' growth. We present only mean target growth per plot here.

\section{Target response competitive ability}

We standardized target performance (relative growth and proportion survival) in the presence of neighbors to performance in the absence of neighbors to quantify response to competition from all surrounding vegetation, using the natural-log transformed response ratio (ln RR) as recommended by Hedges et al. (1999):

$$
\begin{aligned}
\ln \mathrm{RR}=\ln ( & \text { target performance } \\
& \text { with neighbors } \\
& \div \text { target performance } \\
\text { without neighbors } &
\end{aligned}
$$

Values of $\ln \mathrm{RR}$ are symmetrical around 0 , with positive values indicating facilitation and negative values indicating competition. The response ratio was always calculated within an abiotic environment within each block. In a few instances when all individuals died in a no-neighbor plot (6 of 48 plots), we estimated ln RR growth for that block by using the mean no-neighbor growth across all of the other blocks. Because the survival data contained zeros, we added a one to both the numerator and denominator before taking the natural $\log$ when calculating the $\ln$ RR for survival.

\section{Effects of treatments on neighborhood and abiotic environment}

In each year, we measured neighborhood and environmental characteristics in each plot to determine whether the treatment manipulations influenced the plots as we had intended. All parameters were measured for each plot ( $n=240$ plots; transplant control plots were excluded) except for nitrogen measurements. Due to time constraints, one plot from each treatment per block was randomly selected to be sampled for nitrogen, regardless of target-species identity $(n=80$ plots $)$.

We measured light availability (PAR, photosynthetically active radiation) during midday between 1000 and 1400 on 11 and 12 July 1997 and again on 15 and 16 July 1998, with a Sunfleck Ceptometer (Decagon, Pullman, Washington, USA). We measured PAR at ten random point positions in each plot $5 \mathrm{~cm}$ above the ground and then took ten readings at chest height (1.4 $\mathrm{m})$ above the vegetation. We treat the proportion of the mean PAR at target height to the mean PAR at chest height as a measure of available light for the target plant. Neighbor vegetation and litter were harvested by clipping during the final target harvest on 19-20 September 1998. Samples were dried to a constant mass and weighed. Maximum neighbor height was measured as the mean of the five tallest neighbor shoots in each plot during the interim and final target harvest.

We visually estimated the percent cover of each neighbor species for each plot during 1-5 August 1997 and 3-8 August 1998. Specimens of all species present as neighbors have been submitted to the University of Michigan Herbarium as voucher specimens. We considered the eight species with the highest percent cover in control (AM neighborhood) plots as representative matrix species. These species were Andropogon gerardii, Coreopsis tripteris, Eupatorium altissimum, Onosmodium molle, Pycnanthemum tenuifolium, Silphium terebinthinaceum, Sorghastrum nutans, and $\mathrm{Zi}$ - 
zia aurea (nomenclature follows Voss [1972, 1985, 1996]). The percent cover of these matrix species relative to total neighbor cover in a plot constituted our measure of matrix species abundance.

Soil compaction (pressure required to penetrate, in pascals) was measured at the center of each plot with an S-170 penetrometer (Boart Longyear, Stone Mountain, Georgia, USA) on 12 July 1997, 20 August 1997, and 7 July 1998. Nitrogen mineralization was measured using the buried bag method (Hart et al. 1990). Polyethylene bags containing soil cores were buried and initial soil core samples taken 1 September 1997; the incubated soil cores were collected on 1 June 1998 after overwintering in situ. Approximately $10 \mathrm{~g}$ oven-dry equivalent of soil was extracted in $2 \mathrm{~mol} / \mathrm{L} \mathrm{KCl}$ within $24 \mathrm{~h}$ of collection. The supernatant was refrigerated 23 wk until analysis for ammonium and nitrate at the Michigan State University Soil and Plant Nutrient Laboratory, East Lansing, Michigan. The initial measurement (1 September 1997) was used to estimate the available N pool. Soil moisture was measured on 15 August 1997 and 12 August 1998 using a TDR soil moisture measuring system (Tektronix, Beaverton, Oregon, USA). We calibrated the TDR using the wet and oven-dry masses of additional soil samples collected at the prairie the same day.

\section{Statistical analyses}

Statistical analyses were done using SYSTAT 5.05 for Windows (Wilkinson 1990). Relative growth and response ratios were natural log transformed; no other departures from the assumptions of normality and homogeneity were evident. Because sample sizes were often unequal, Type III sums of squares were used in all analyses. Four sets of analyses were performed.

First, to test the effectiveness of the experimental treatments, we analyzed the neighborhood characteristics in a fully crossed ANOVA model with species (Andropogon, Coreopsis, and Ratibida), neighborhood type (adult matrix, reduced adult matrix, juvenile matrix, juvenile colonist), and abiotic alteration (no mound, mound) as fixed factors. Soil characteristics were analyzed in similar models, with the addition of the no-neighbor neighborhood type. Due to subsampling, we could not assess the effect of target-species identity on nitrogen measurements. These ANOVAs allowed us to confirm that the actual affects of our manipulations were what we intended.

Then, to understand how the target species differ from each other and respond to mound formation in the absence of interactions, we analyzed potential performance in the no-neighbor plots, using ANOVA models with species identity (Andropogon, Coreopsis, and Ratibida) and abiotic alteration (no mound, mound) as fixed factors. These analyses and all those on competitive intensity and competitive hierarchies described below were performed for both survival and relative growth rate as two distinct measures of individual performance.

To understand the effects of gap creation overall on competition intensity and competitive hierarchies, we compared target species responses (ln RR) in matrix conditions (AM neighborhood, no mound) with gap conditions (RJC neighborhood, mound). Although this comparison was part of the larger factorial design, experimentwise error rate was not adjusted because it did not exceed the within-group degrees of freedom (Sokal and Rohlf 1995). Significant main effects of species indicate the existence of a distinct competitive hierarchy, i.e., differences in competitive ability among species, regardless of environment. Significant interactions between gap creation and species indicate changes in competitive hierarchies between gap and matrix conditions, while main effects of gap creation are interpreted as differences in overall competition intensity between gap and matrix conditions.

Finally, to separate neighborhood and abiotic effects on competitive hierarchies and competition intensity, we analyzed standardized target performance (ln RR) in a fully crossed ANOVA model with species ( $A n$ dropogon, Coreopsis, and Ratibida), neighborhood type (adult matrix, reduced adult matrix, juvenile matrix, and juvenile colonist), and abiotic alteration (mound, no mound) as fixed factors. Tukey multiple comparison tests were performed in cases of significant species or species $\times$ treatment effects to determine species competitive rankings.

As part of the analysis of the entire set of factorial manipulations, we conducted a series of planned comparisons to determine the particular components of gap creation that were responsible for any changes in competitive hierarchies. We first compared (1) the AM and RJC neighborhoods for the overall neighborhood effect, (2) the AM and RAM neighborhoods for the effect of biomass reduction, (3) the RAM and RJM neighborhoods for the effect of size structure, and (4) the RJM and RJC neighborhoods for the effect of neighbor identity. All neighborhood effects were assessed at both levels of abiotic soil alteration (no mound, mound). Then we assessed the effect of abiotic mound formation by comparing no-mound and mound abiotic soil conditions for each neighborhood type. The neighborhood and abiotic comparisons were not orthogonal so we used a Bonferroni-adjusted experimentwise error rate (alpha divided by number of comparisons) of 0.0125 . For both the effects from the entire ANOVA model and the planned comparisons, interpretations of significant effects are similar to those for the overall effects of gap creation; significant interactions between species and neighborhood type or abiotic alteration indicate changes in competitive hierarchies, while main effects of either of these factors indicate changes in competition intensity. 

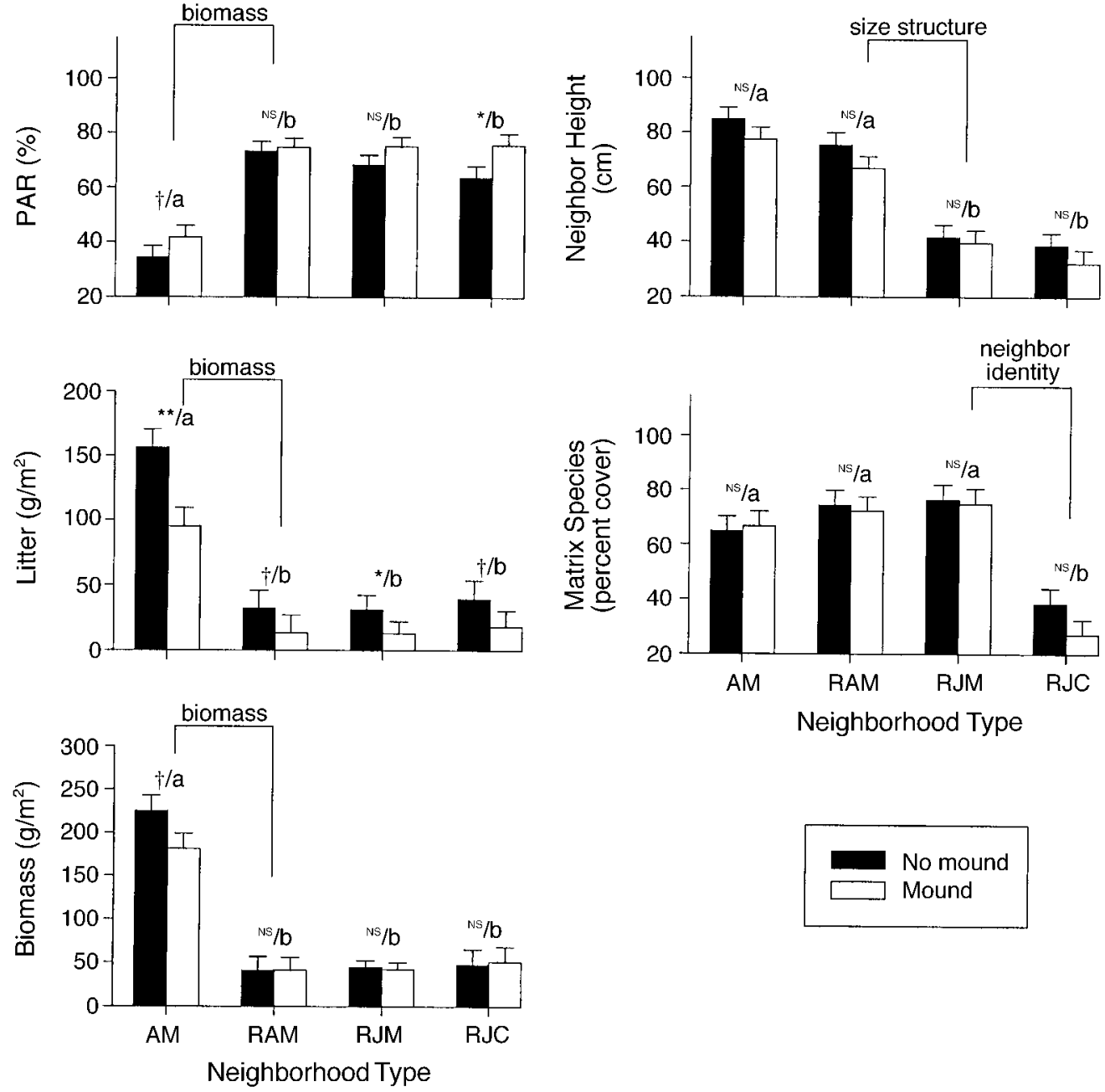

FIG. 3. The effect of experimental treatments on neighborhood characteristics: light availability, litter mass, live biomass, maximum neighbor height, and percentage matrix species (mean and $1 \mathrm{SE}$ ). The neighborhood types are abbreviated as follows: adult matrix (AM), reduced adult matrix (RAM), juvenile matrix (RJM), and juvenile colonist (RJC). The effect of abiotic soil alteration, adjusted for multiple comparisons, is shown for each neighborhood type $(\dagger P<0.10 ; * P<0.05$; ** $P$ $<0.01 ; * * * P<0.001)$. Different lowercase letters above the histogram bars indicate differences among neighborhoods; specific disturbance effects are also indicated by brackets. There were no significant interactions between neighborhood and abiotic alteration, nor any significant target-species effects. The overall effect of gap creation (comparison of AM/no mound with RJC/mound, see Fig. 2$)$ was significant $(P<0.001)$ for all variables shown here. Error degrees of freedom range from 160 to 150; factor degrees of freedom are in Table 1.

\section{RESULTS}

\section{Effects of treatments on neighborhood and abiotic conditions}

Results for treatment effects on neighborhood and abiotic conditions were very similar in the two years of the experiment (Suding 1999); therefore only results from the second year (1998 growing season) are presented in detail. The creation of gaps (comparison of $\mathrm{AM} /$ no mound to RJC/mound treatments), as well as the separate components of gap creation, significantly changed almost all of the measured neighborhood and abiotic parameters in the expected directions (Figs. 3 and 4). Overall, compared to the undisturbed matrix conditions, the experimentally created gaps had reduced biomass (both living biomass and litter) and consequently more light, as well as shorter neighbors and reduced percent cover of matrix species (Fig. 3). Gaps also had less soil moisture, probably a consequence of reduced soil compaction, although they did not differ from matrix conditions in the available $\mathrm{N}$ pool nor the rate of nitrogen mineralization (Fig. 4).

In addition, the treatments were mostly, although not entirely, successful in separating the components of gap creation so that the effects of each could be assessed while holding other components constant (see Fig. 2). Neighbor height significantly differed only between juvenile (even-size) and adult (uneven-size) neighbor- 

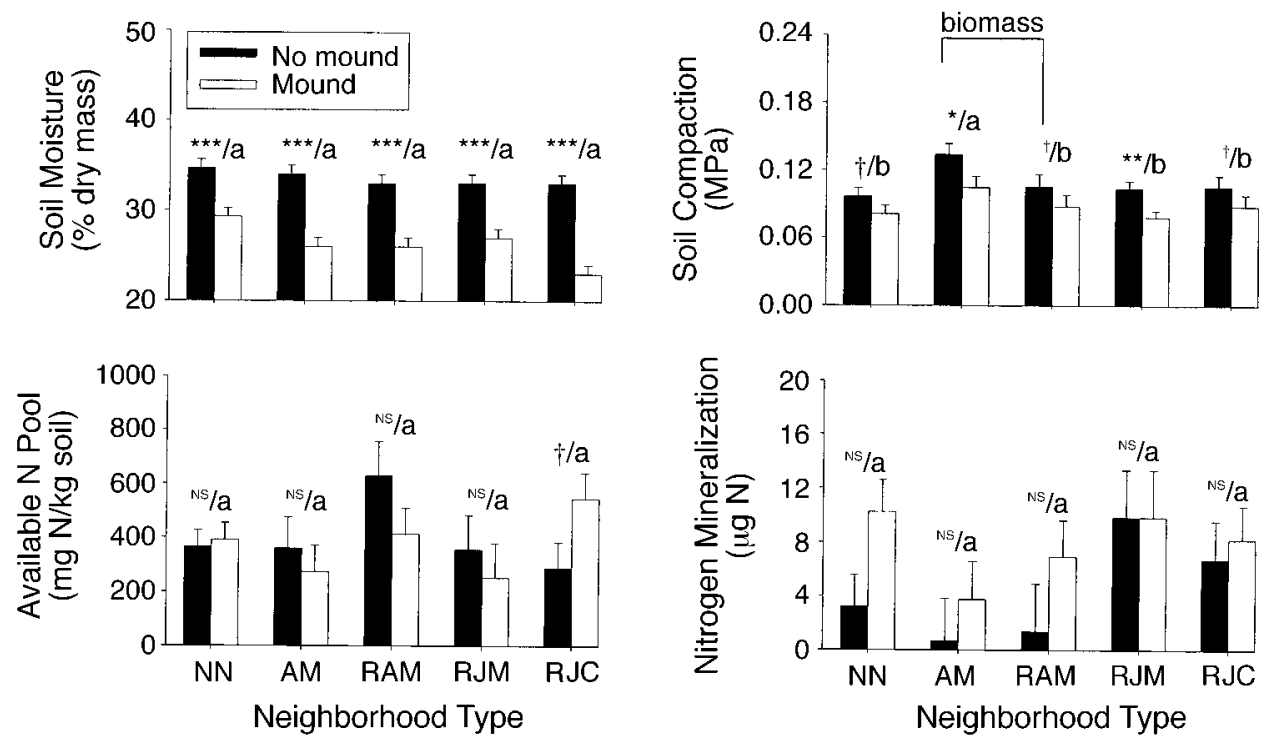

FIG. 4. The effect of experimental treatments on soil environmental characteristics: soil moisture, soil compaction, available soil $\mathrm{N}$ pool, and nitrogen mineralization (mean and $1 \mathrm{SE}$ ). $\mathrm{NN}=$ no-neighbors treatment. Other symbolism is as in Fig. 3. The effect of abiotic soil alteration, adjusted for multiple comparisons, is shown for each neighborhood type ( $\dagger P$ $<0.10 ; * P<0.05 ; * * P<0.01 ; * * * P<0.001)$. Different lowercase letters indicate significant differences among neighborhoods and are related to specific disturbance effects by brackets. There were not any significant interactions between neighborhood and abiotic alteration, nor any significant target-species effects. The overall effect of gap creation (comparison of AM/no mound with RJC/mound, see Fig. 2) was significant $(P<0.001)$ for soil moisture and soil compaction. Error degrees of freedom are 159 for soil moisture and compaction, 33 for available $\mathrm{N}$ pool, and 29 for $\mathrm{N}$ mineralization; factor degrees of freedom are as in Table 1.

hoods (Fig. 3), species identity (percent cover of matrix species) significantly differed only between all the designated matrix neighborhoods and the designated colonist neighborhood (Fig. 3), and soil compaction and moisture differed between mound and no-mound conditions (Fig. 4). The major exception to the clean experimental separation of disturbance components is that creation of mounds (abiotic soil alteration) tended to decrease litter and sometimes biomass, and consequently tended to increase light (Fig. 3), indicating mounds are less favorable environments for growth than matrix conditions. Although this pattern was consistently significant in the adult matrix neighborhoods and sometimes occurred in the other neighborhoods as well, the magnitude of the effect was small in comparison to the effect of the intended neighborhood manipulations.

\section{Target performance in the absence of interactions}

For survival in the absence of neighbors, the three species did not differ significantly overall or in response to abiotic alteration. The survival of Andropogon, but not the two forbs, tended to be lower on mounds during the second growing season (Fig. 5).

In contrast, for relative growth in the absence of neighbors, the three species differed strongly. In the second year, they also responded differently in terms of growth to abiotic soil alteration (significant species and species $\times$ abiotic interaction, Fig. 5). In soil en- vironments without mound alteration, Ratibida grew faster than Coreopsis and both forb species grew faster than Andropogon (Fig. 5). Although this ranking of growth rate was similar in mound soil environment, Andropogon growth declined even further in mound conditions, while Ratibida and Coreopsis were less affected (Fig. 5). Compared to the forb species, Andropogon also grew significantly slower belowground but had the greatest allocation to roots and the highest specific leaf area of the three species (Suding 1999).

\section{Overall gap effect on competition intensity}

The effects of neighbors on survival were not significantly different from zero in either year, indicating that neighbors had either minimal or counteracting facilitative and competitive effects on survival. Furthermore, the magnitude of neighbor effects on survival did not change between matrix and gap conditions (nonsignificant effect of gap creation, Fig. 6), although effects tended to be slightly more negative in the second year, especially under matrix conditions. In contrast, neighbors generally inhibited the relative growth of targets. In both years, the intensity of competition was greater under matrix conditions than under gap conditions (Fig. 6). Neighbors had minimal, if any, effects on target relative growth the first year under gap conditions, but by the second year neighbors did significantly inhibit target growth under gap condi- 

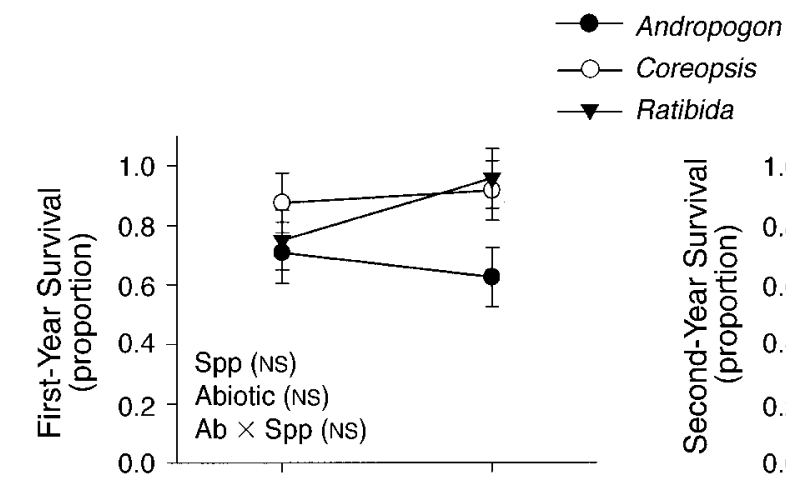

$\checkmark$ Ratibida
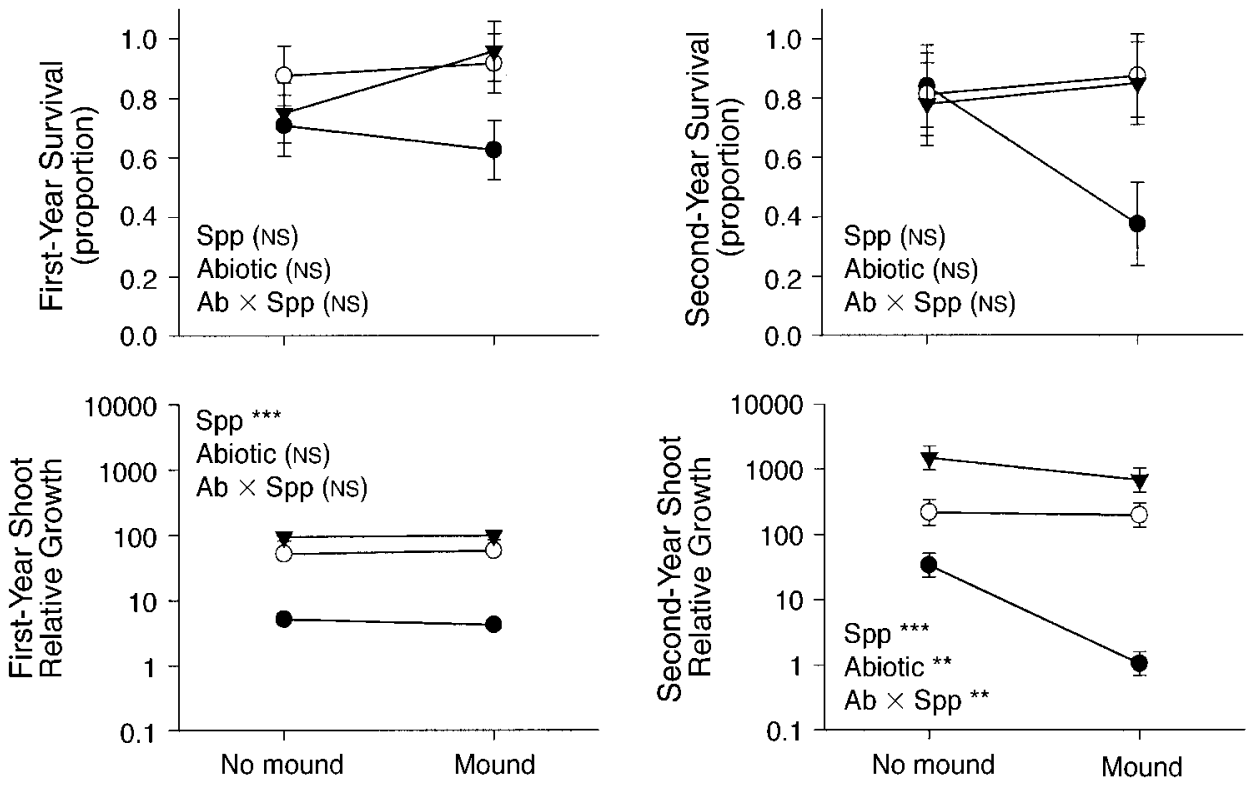

Abiotic Soil Environment

FIG. 5. Survival (proportion) and relative growth (g growth/g initial biomass) of the three target species in the absence of interactions (NN neighborhood, Fig. 2) under no-mound and mound conditions (mean $\pm 1 \mathrm{SE}$ ). Note log scale for relative growth. Statistical results are from two-way ANOVAs of abiotic environment (no mound, mound) and target species $(* P<$ 0.05 ; ** $P<0.01$; *** $P<0.001$; NS, not significant, $P>0.05$ ). Error degrees of freedom range from 32 to 35 .

tions. The intensity of competitive interactions in matrix conditions was also stronger in the second year.

\section{Overall gap effect on response competitive hierarchies}

A strong hierarchy for growth response formed in matrix conditions (AM neighbors, no mound), with the effect of neighbors most severe on the growth of $A n$ dropogon and least severe on Coreopsis, especially after two years (Fig. 6). This strong hierarchy for growth broke down under gap conditions, with the three target species having similar competitive abilities. Although this shift in competitive rankings was only significant the second year, the rankings in the first year followed a similar pattern (Fig. 6). Thus, while the competitive growth hierarchies changed, supporting the competitive change hypothesis, it was a change from distinct hierarchies to competitive equivalence rather than a reversal in rankings as predicted in Fig. 1. Target species did not differ in their survival response to neighbors in either year or in either gap or matrix conditions (although differences were evident in the analysis of the entire factorial design: see next section).

\section{Separating effects of components of gap creation on competitive interactions}

The effects of different components of gap creation were qualitatively similar between the two years, al- though the influence of treatments on species rankings became statistically apparent only in the second year (interactions in Table 1). Here we focus on second-year results, which tended to be quantitatively stronger (as in the overall gap vs. matrix comparisons in Fig. 6). For survival, neighborhood type influenced neither the intensity nor the hierarchy of neighbor effects (Table 1, Fig. 7). However, abiotic conditions did weakly but significantly change the competitive hierarchies but not overall interaction intensity (Table 1). While there was no defined hierarchy for survival under unaltered (nomound) soil conditions, under altered soil conditions (mounds) a hierarchy formed in which Andropogon was significantly less affected by competition compared to Coreopsis (Table 1). Ratibida had an intermediate response that did not significantly differ from that of either of the other species. This effect of soil alteration on survival rankings was generally weak but consistent in each neighborhood type (Fig. 8).

In contrast, for relative growth, neighborhood type strongly affected overall competitive intensity (Table $1)$; the biomass reduction that typically follows a disturbance reduced competition intensity, while having neighbor species typical of gaps actually increased competition intensity (Fig. 7). Size structure had no effect on competition intensity in terms of growth. Abiotic soil alteration did not influence the effects of neighborhood type (Table 1). Although neighborhood 

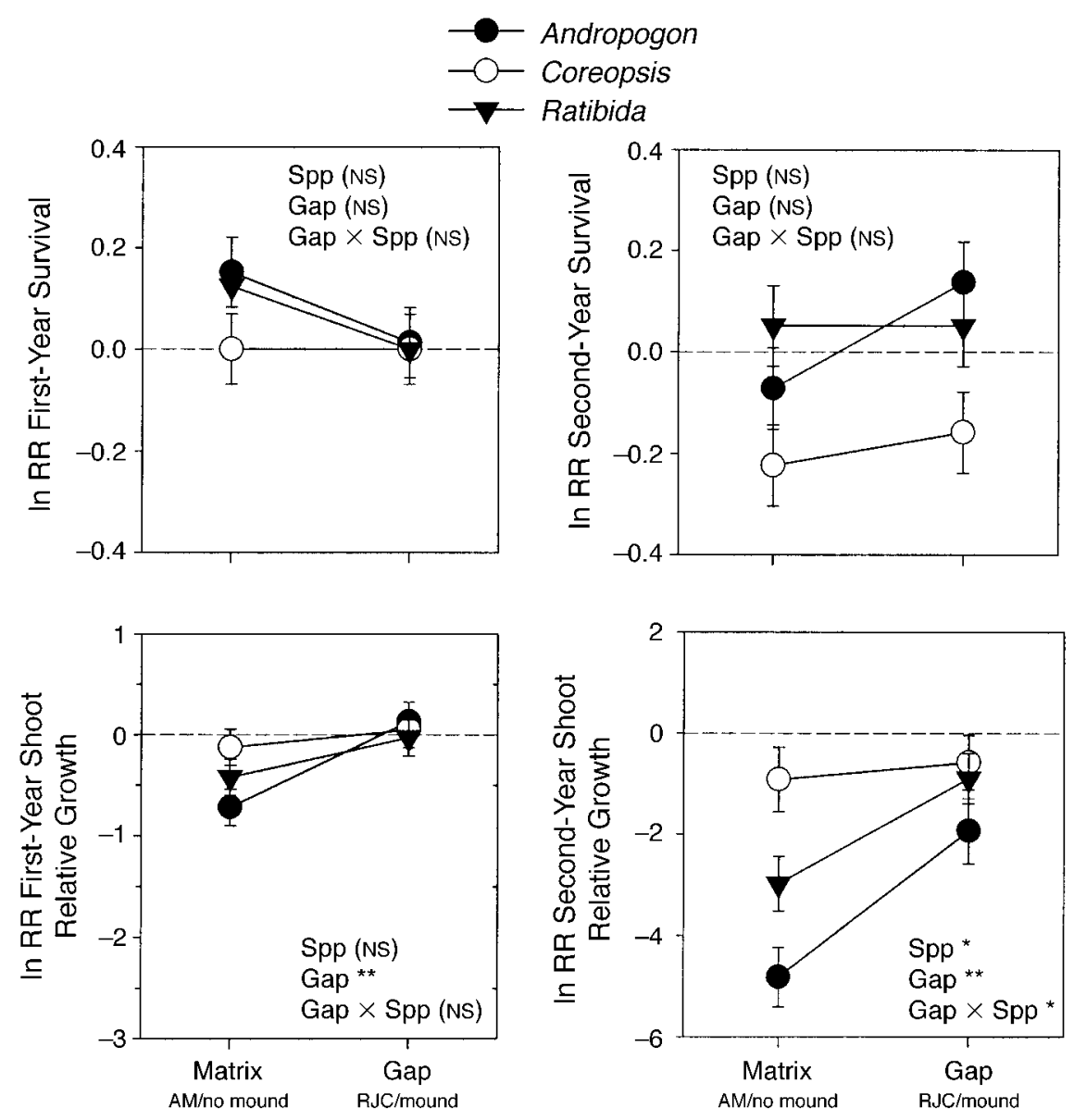

Overall Gap Creation

FIG. 6. The overall effect of gap creation on the competitive response (ln RR for survival and relative growth; mean \pm $1 \mathrm{SE})$ of the three target species in both years $(* P<0.05 ; * * P<0.01 ; * * * P<0.001$; NS $=$ not significant, $P>0.05)$. Matrix conditions are the combination of AM neighborhood type and unaltered soil environment; gap conditions are the combination of RJC neighborhood type and altered soil environment. Error degrees of freedom range from 34 to 36.

TABLE 1. The effect of experimental treatments (neighborhood type and abiotic soil environment) on competitive response (ln RR) calculated from survival and growth of target plants in the first and second year.

\begin{tabular}{|c|c|c|c|c|c|}
\hline \multirow[b]{2}{*}{ Source of variation } & \multirow[b]{2}{*}{ df } & \multicolumn{2}{|c|}{ ln RR survival } & \multicolumn{2}{|c|}{ ln RR relative growth } \\
\hline & & 1 st year & 2nd year & 1st year & 2nd year \\
\hline Block & 7 & 1.01 & 0.56 & $3.97 * *$ & $2.30 *$ \\
\hline Species (Spp) & 2 & $8.04 * * *, \mathrm{a}$ & $7.54 * *$ & $6.24 * *, \mathrm{c}$ & $8.87 * * *$ \\
\hline Abiotic soil environment (Ab) & 1 & $4.31 *$ & 2.35 & $4.22 *$ & 4.25 \\
\hline Overall neighborhood (Nbh) & 3 & 0.08 & 1.71 & $3.24 *$ & $13.79 * * *$ \\
\hline $\mathrm{Spp} \times \mathrm{Ab}$ & 2 & 0.94 & $4.33 *, \mathrm{~b}$ & 2.57 & $9.64 * * *, \mathrm{~d}$ \\
\hline $\mathrm{Spp} \times \mathrm{Nbh}$ & 6 & 0.24 & 0.71 & 0.30 & 1.72 \\
\hline $\mathrm{Ab} \times \mathrm{Nbh}$ & 3 & 1.43 & 0.66 & 0.85 & 1.93 \\
\hline $\mathrm{Spp} \times \mathrm{Ab} \times \mathrm{Nbh}$ & 6 & 0.68 & 0.44 & 0.65 & 1.31 \\
\hline Error df & & 160 & 160 & 146 & 135 \\
\hline Species rankings & & ${ }^{\mathrm{a}} A=R>C$ & $\begin{array}{l}\text { 'NM: } A=C=R \\
\text { M: } A=R>C=R\end{array}$ & ${ }^{\mathrm{c}} \mathrm{C}>R>A$ & $\begin{array}{l}\mathrm{dNM}: C>R>A \\
\mathrm{M}: A=C=R\end{array}$ \\
\hline
\end{tabular}

Notes: The $F$ ratio and significance level $(* P<0.05 ; * * P<0.01 ; * * * P<0.001)$ are given for each factor. Species rankings are given for either significant species main effects or species $\times$ treatment interactions, as indicated by superscript letters (Tukey multiple comparisons, $P<0.05$ ). $\mathrm{NM}=$ no mound (unaltered soil abiotic environment); $\mathrm{M}=$ mound (altered soil abiotic environment); $A=$ Andropogon, $C=$ Coreopsis, and $R=$ Ratibida). Statistical results for the planned comparisons (as in Fig. 2) are shown in Figs. 6-8. 


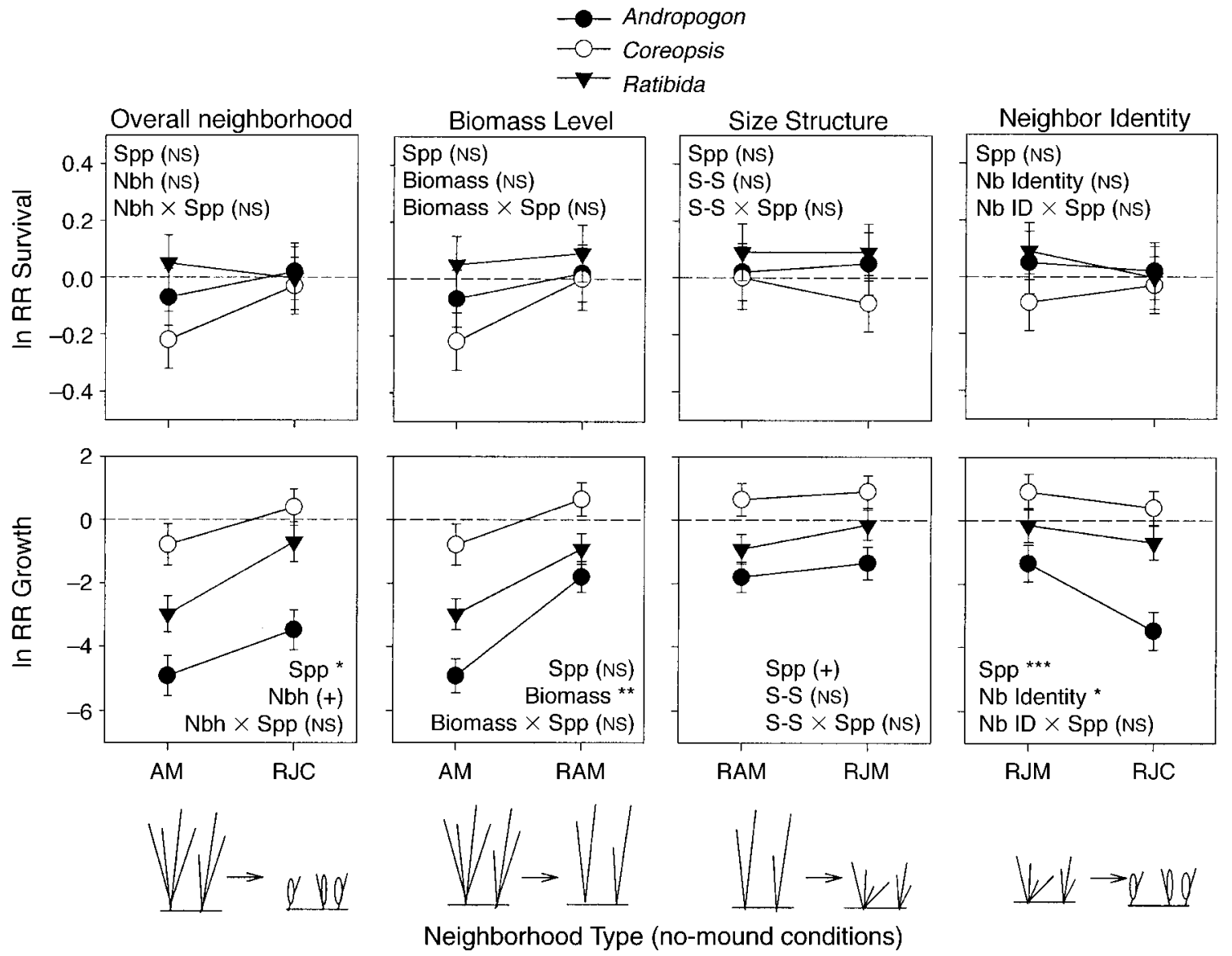

FIG. 7. The influence of neighborhood aspects (overall neighborhood [Nbh], biomass, size structure [S-S], and neighbor identity [Nb ID]) on the effect of neighbors on 2 nd-yr survival and 2 nd-yr relative growth (ln RR; mean \pm 1 SE). Data are shown only for no-mound conditions; neighborhood effects under mound conditions are included in Fig. 8. Specific comparisons and their results are shown in each graph (Bonferroni-adjusted experimentwise error rates; $* P<0.05 ; * * P<0.01$; *** $P<0.001$; NS $=$ not significant, $P>0.05$ ); the overall effects are shown in Table 1 . Although we do not show these effects under mound conditions, the results are similar (there are no significant interactions between neighborhood and abiotic effects for any variable). Error degrees of freedom range from 30 to 35 .

effects changed overall competitive intensity, the competitive hierarchy remained constant regardless of neighborhood type (Table 1 and Fig. 7). Regardless of neighborhood type, Coreopsis was always least affected by neighbors, Ratibida had intermediate competitive response ability, and Andropogon was always the most affected by neighbors (Fig. 7). This concordance of competitive rankings among neighborhoods supports the predictions of competitive reduction (as in Fig. 1).

However, the effect of abiotic conditions on growth response were opposite that of neighborhood type. Abiotic alteration weakly affected overall intensity in the first year (Table 1) but strongly influenced competitive hierarchies by the second year (Table 1, Fig. 8). In all four neighborhood types, target species responded more similarly to neighbors under mound conditions, thereby breaking down the competitive response hierarchy in no-mound conditions to competitive equiv- alence in mound conditions (Fig. 8). This shift in hierarchy caused by abiotic alteration is similar to the shift seen in the overall gap effect (Fig. 6), indicating that abiotic soil alteration is responsible for the changes in competitive rankings due to gap creation.

\section{Discussion}

First, we asked if competitive hierarchies change due to gap creation and found that indeed they do. For growth, a well-defined competitive hierarchy under matrix conditions broke down in gap conditions. For survival, although the interactions were weaker and sometimes facilitative rather than competitive, the response hierarchy became more distinct in gap conditions relative to matrix conditions. While these results appear to support predictions of competitive change in that hierarchies are not concordant in matrix and gap conditions, a prediction of competitive reduction that matrix species were always competitively superior to gap 


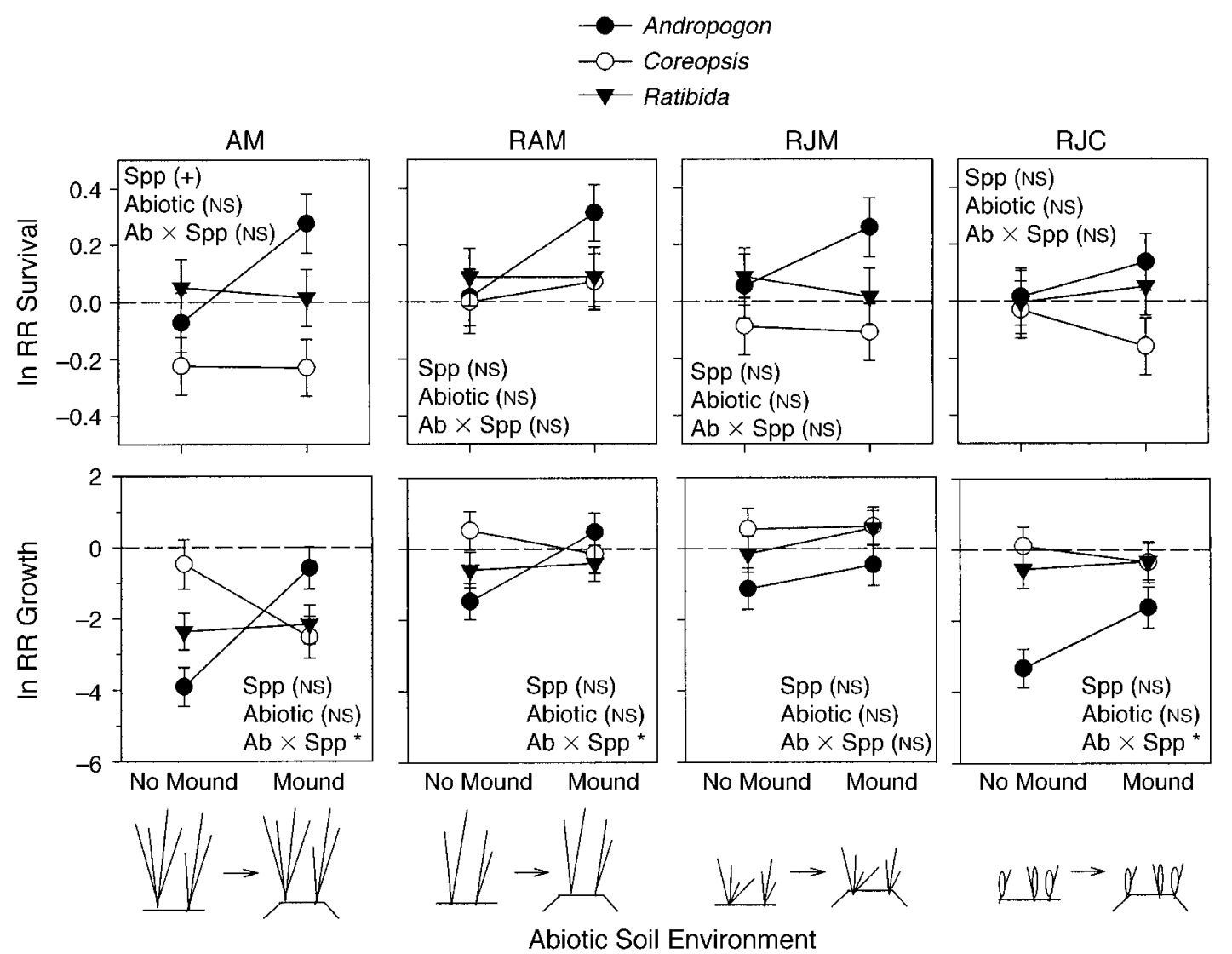

FIG. 8. Effects of abiotic soil alteration (mound formation) on competitive interactions for each neighborhood type (ln RR 2nd-yr survival and 2nd-yr relative growth; mean $\pm 1 \mathrm{SE}$ ) for the three target species. Specific comparisons and their results are shown for each neighborhood type; the overall effects are shown in Table 1. Error degrees of freedom are 2935 for each neighborhood type (Bonferroni-adjusted experimentwise error rates; $* P<0.05$; ** $P<0.01 ; * * * P<0.001$; NS $=$ not significant, $P>0.05)$.

species, was also confirmed. Although the same matrix species did not remain dominant in both matrix and gap conditions, a matrix species was always competitively superior under conditions where the hierarchies were distinct. Thus, while hierarchies did change, the change reflected a trade-off between growth and survival competitive strategies for matrix species.

Given the changes in competitive hierarchies following gap creation, we then asked what mechanism could account for the changes. Shifts in species rankings were due exclusively to changes in abiotic, rather than neighborhood, conditions, even though neighborhood changes influenced overall competition intensity. In the sections below we discuss these results in more detail and their implications for understanding how and why disturbance influences community structure.

\section{Shifts in competitive response hierarchies}

Our results were inconsistent with one key assumption of the competition-reduction hypothesis, that competitive hierarchies remain unchanged following a disturbance. For both survival and growth, we found a change from distinct hierarchies to competitive equiv- alence. Although we predicted a complete reversal in rankings (as in Fig. 1), these changes broadly support the competitive change hypothesis.

Interestingly, survival and growth differed in whether the hierarchies were more distinct under matrix conditions (growth) or under gap conditions (survival). The explanation of this difference may lie in the fact that the gaps we studied were actually more stressful environments, particularly for the matrix grass Andropogon: in the absence of neighbors, mound formation diminished the survival and growth of Andropogon but did not affect Coreopsis and Ratibida. This difference among species may be because Andropogon juveniles are less tolerant of the lower soil moisture of the mounds (see Fig. 3) compared to the forb species or because Andropogon is obligately mycorrhizal and may have been more affected by the physical breakup of the hyphal network during mound formation (Hetrick et al. 1994).

In environments such as the mounds that are more stressful for some species than others, a species' stress tolerance may influence its relative competitive ability. If stress strongly diminished survival (as in the case 
of Andropogon), competition may have less capacity to diminish survival further because strong abiotic effects would dwarf any neighbor effects. Thus, species that are not able to tolerate the stresses of the mound environment may not be able to respond to neighbors and so actually have high competitive response abilities, as they are usually defined. In contrast, more tolerant individuals would not experience high mortality and so neighbors may have the potential to influence their survival to a greater degree (as in the case of Coreopsis). This influence of tolerance on competitive response ability may be responsible for the development of a survival competitive hierarchy in gaps.

In contrast to these results for survival, competition inhibited the growth of Andropogon to the same degree as the other species: a growth hierarchy did not develop in gap conditions. Hence, while tolerance appears to influence competitive survival response, it does not appear to influence competitive growth response. This distinction may reflect differences in the factors that cause species to diverge in competitive ability: survival competitive responses may diverge when constraints are imposed by the physical environment while growth competitive response may diverge only in the absence of these physical constraints. Other studies have also found competitive equivalence in gap conditions when using growth as a measure of response (Rabinowitz and Rapp 1985a, McConnaughay and Bazzaz 1990, Kupfer and Runkle 1996, but see Platt and Weis 1985). Equivalence may indicate that gap conditions are often stressful and these physically stressful conditions constrain species to be similar in competitive ability.

In environments with no mounds, survival did not differ among species, either in the absence or presence of neighbors, possibly because the influence of physical constraints was minimal. Consequently, species did not differ in their competitive ability in terms of survival. However, they did differ in their growth responses to competition under matrix conditions, producing a distinct growth, rather than survival, hierarchy.

When disturbances do not represent stressful environments for species, we might expect to see less distinct rankings in survival competitive response due to weaker physical constraints. Rather, a complete competitive reversal in growth hierarchies due to gap creation may occur, reflecting differential species response to different competitive environments. K. N. Suding (unpublished manuscript) found that, although Andropogon and Ratibida seedlings were competitively equivalent in terms of survival in experiments conducted in each of three years following a fire disturbance, their growth rankings completely reversed over the same period. Thus, if gaps are physically stressful, there may be a trade-off between matrix growth and gap survival hierarchies, while if gaps are not stressful, the trade-off may be between matrix and gap growth hierarchies. These two kinds of trade-offs, although possibly quite general, have not been tested.

\section{Shifts in competitive superiority}

Based solely on whether hierarchies change or not due to gap creation, our results are consistent with the competitive change hypothesis. However, the hypotheses predict not just whether rankings will change, but which species will be competitively superior in matrix and gap conditions. Taken separately, species rankings in terms of either survival or growth are largely inconsistent with both hypotheses. First, for growth under gap conditions and for survival under matrix conditions, no competitive hierarchy at all is apparent (see Figs. 6 and 8). For growth under matrix conditions, although we did find that the matrix forb, Coreopsis, was competitively superior, the much more abundant matrix grass, Andropogon, was competitively inferior. For survival under gap conditions, Andropogon was competitively superior.

These inconsistencies with both hypotheses can be at least partially resolved by considering competitive ability in terms of survival and of growth as two alternative competitive strategies used by different matrix species. A matrix species was always competitively dominant, although which matrix species depended on whether the plants were growing under matrix or gap conditions. In this view, the results support the idea of competitive reduction.

An individual may be a superior response competitor by two different strategies: either have higher resource uptake rates or have lower resource loss rates (Goldberg 1990, 1996). The growth strategy of Coreopsis may be very successful if it is able to maintain relatively high uptake rates and grow quickly to reproductive maturity. It tends to be an aggressive clonal invader of restored prairie areas, able to quickly colonize and spread (Schramm 1978, Suding 1999). However, under situations where it is not able to maintain high uptake rates (due to external factors like intense herbivory or intervals of highly stressful environmental conditions), its population growth may slow (Goldberg and Novoplansky 1997). Andropogon's survival strategy may be beneficial if it is able to slow resource loss and, while taking a longer time to grow, eventually become abundant (Tilman and Wedin 1991).

Late successional species, although abundant under matrix conditions, might be poor competitors when assessed in terms of short-term growth responses to neighbors (Rabinowitz et al. 1984, Duralia and Reader 1993, Sullivan and Peterson 1994). Other studies have found similar trade-offs between survival and growth competitive abilities (McConnaughay and Bazzaz 1990, De Steven 1991, Gill and Marks 1991, Burton and Bazzaz 1995), suggesting that competitive hierarchies may often differ between these demographic parameters. While matrix species are usually competitively superior to disturbance species, we hypothesize that matrix and gap conditions (particularly gap con- 
ditions that are physically stressful) differ in which competitive strategy confers success.

\section{Shifts in the overall intensity of interactions}

In addition to effects on competitive hierarchies and species rankings, gap creation also reduced the intensity of competitive effects on growth, although not on survival. Both hypotheses share the assumption that disturbance reduces the overall intensity of competitive interactions; this result is not surprising and supports the findings of other studies (e.g., Wilson and Keddy 1986, Campbell and Grime 1992, Turkington et al. 1993, but see Wilson and Shay 1990).

The intensity of neighbor effects on target survival, under both matrix and gap conditions, were generally much weaker in magnitude than those on relative growth. While neighbors exert either minimal or a mixture of offsetting facilitative and competitive effects on survival, neighbors exert more exclusively competitive effects on growth. Even though the overall intensity of effects on survival were weak, these effects could still have consequences to net individual fitness greater than or equal to those on growth (McPeek and Peckarsky 1998). To determine the relative contributions of these responses to changes in relative abundance, demographic analyses of particular populations are needed. Alternatively, although logistically difficult, measuring changes in relative abundance (i.e., community-level responses) would more directly incorporate both growth and survival individual-level responses (Goldberg et al. 1995).

\section{Mechanisms of competitive change}

While we found partial support for both hypotheses concerning how competitive interactions change due to gap creation, the mechanisms that account for these changes were very clear. The controls on species competitive rankings were largely independent from the controls on the overall intensity of competition. While neighborhood changes (lower biomass, colonist neighbor species; Fig. 3) affected competitive intensity for growth, abiotic soil alteration (primarily lower soil moisture and compaction, Fig. 4) was responsible for shifting competitive hierarchies for both growth and survival. The control by abiotic soil alteration of competitive hierarchies again indicates that stress tolerance may play a role in determining competitive rankings in gaps.

This unexpected but clean separation of neighborhood and abiotic controls on competitive interactions highlights the critical importance of breaking down particular disturbances into specific components of change. Furthermore, it suggests that inclusion of some of this complexity in our conceptual models of disturbance will assist our ability to predict the influence of a particular type of disturbance. Identification of particular aspects of complex disturbances that are important in maintaining species persistence and overall diversity is critical for many communities where humans have altered natural disturbance regimes (i.e., "designed disturbance" sensu Hobbs and Norton [1996]).

Our results indicate that the effects of a particular disturbance may be predicted based on the degree to which it alters neighborhood and abiotic characteristics. For example, a disturbance that predominantly changes neighborhood structure (such as grazing or mowing) may not change competitive rankings but just reduce competitive intensity. Thus, we would predict that species that are competitively superior in ungrazed conditions would also be superior in grazed conditions. Superior colonists would only be able to persist in grazed areas where competitive intensity is low. However, disturbances such as tilling that alter the abiotic soil environment as well as reduce neighbor biomass may alter species competitive rankings. In this case, the altered competitive rankings, not solely colonization ability, would determine abundance in gap conditions. Further experiments with different types of disturbances and different sets of species are needed to determine whether other types of environmental alteration have the potential to affect hierarchies.

Although we examined changes in competitive interactions due to soil mound disturbance, these results also have implications for changes in competitive interactions along environmental gradients. In studies that have tested whether competitive response hierarchies change between environments, results are inconsistent (Goldberg 1996). One reason for this inconsistency may be the relative importance of neighborhood vs. abiotic changes across each gradient. When mostly neighborhood conditions change (e.g., gradients in standing crop across one site or due to nitrogen addition), hierarchies may not change. Competitive interactions along this type of gradient would be similar to when we only altered neighborhood characteristics and found that they did not change hierarchies. However, in gradients in which the abiotic environment changes irrespective of neighborhood characteristics (e.g., gradient among sites that differ in soil type or topography), hierarchies may have a greater potential to change and thus competition may play a larger role in explaining patterns of species abundances among environments.

\section{Implications for disturbance ecology}

Our results have important implications for both theoretical and empirical research in disturbance ecology. First, although our results are broadly consistent with the competitive reduction hypothesis, they also suggest that some aspects of the current conceptual framework should be reconsidered. Disturbance may often change species competitive rankings between a distinct hierarchy and competitive equivalence, as we found, or even completely reverse hierarchies in some situations. Conceptual and theoretical models should consider the potential of species competitive rankings to change, in 
addition to overall competitive intensity to diminish, following disturbances that create gaps.

We also found that the identity of the superior competitor depended on the environment and on whether competitive superiority was considered in terms of survival or growth. We hypothesize that trade-offs in survival vs. growth competitive ability exist within a single environment, and the physical constraints of that environment may influence these trade-offs. The implications of such a trade-off for coexistence, both within and among environments, also deserve both empirical and theoretical exploration. Clearly, studies that focus on competitive effects on growth and assume survival is simply a monotonic function of growth (e.g., Tilman 1988, Pacala et al. 1996) may miss important dynamics.

Lastly, by experimentally separating components of a disturbance, we were able to summarize the influence of many aspects of disturbances on competitive interactions into a few discrete mechanisms (neighborhood type, abiotic change) that can be incorporated into models of gap dynamics. We hope this approach helps to bridge the gap between empirical work, which emphasizes that each disturbance type is unique in its complexity, and theoretical work, which largely ignores many of these complexities. The importance of such separation of mechanisms is illustrated by our result that reduction of neighbor biomass following a disturbance was only responsible for changes in the intensity of competition, not for changes in competitive rankings. Instead, changes in rankings were due to alteration of soil abiotic environment.

While strongly suggestive, these conclusions are based on only three species including only one gap species and only one type of disturbance. Clearly, more comparisons are needed to test both the competitive reduction and competitive change hypotheses in their original form, as well as the additional hypothesis of the existence of a trade-off between survival and growth competitive strategies.

\section{ACKNOWLEDGMENTS}

We thank K. Hartman, D. Schoolmaster, S. Fielder, P. Suding, C. Baraloto, S. Corso, and many others for assistance in the field, C. Midkiff for lodging, and the Ohio Department of Natural Resources for permission to work at the site. This manuscript was much improved by comments from V. Allison, J. Courteau, H. de Kroon, D. Greiling, T. Howard, B. Rathcke, S. Wilson, and two anonymous reviewers. This research was supported by NSF Dissertation Improvement Grant DEB 97-01250, a Helen Olson Brower Memorial Fellowship, a Rackham Predoctoral Fellowship, and research grants from the University of Michigan. NSF DEB 98-10218 supported K. Nash Suding while she was writing this manuscript.

\section{Literature Cited}

Aguilera, M. O., and W. K. Lauenroth. 1995. Influence of gap disturbances and type of microsites on seedling establishment in Bouteloua gracilis. Journal of Ecology 83:8797.

Allen, J. C. 1985. Soil response to forest clearing in the
United States and the tropics: geological and biological factors. Biotropica 17:15-27.

Belsky, A. J. 1986a. Population and community processes in a mosaic grassland in the Serengeti, Tanzania. Journal of Ecology 74:841-856.

Belsky, A. J. 1986b. Revegetation of artificial disturbances in grasslands of the Serengeti National Park, Tanzania. I. colonization of grazed and ungrazed plots. Journal of Ecology 74:419-437.

Belsky, A. J. 1992. Effects of grazing, competition, disturbance and fire on species composition and diversity in grassland communities. Journal of Vegetation Science 3: 187-200.

Brewer, J. S., T. Rand, J. M. Levine, and M. D. Bertness. 1998. Biomass allocation, clonal dispersal, and competitive success in three salt marsh plants. Oikos 82:347-353.

Burton, P. J., and F. A. Bazzaz. 1995. Ecophysiological responses of tree seedlings invading different patches of oldfield vegetation. Journal of Ecology 83:99-112.

Bush, J. K., and O. W. Van Auken. 1995. Woody plant growth related to planting time and clipping of $\mathrm{a}_{4}$ grass. Ecology 76:1603-1609.

Campbell, B. D., and J. P. Grime. 1992. An experimental test of plant strategy theory. Ecology 73:15-29.

Chapin, F. S., III. 1980. The mineral nutrition of wild plants. Annual Review of Ecology and Systematics 11:233-260.

Chapin, F. S., III. 1991. Integrated responses of plants to stress. BioScience 41:29-36.

Chazdon, R. L., and N. Fletcher. 1984. Photosynthetic light environments in lowland tropical rain forest in Costa Rica. Journal of Ecology 72:553-564.

Coffin, D. P., and W. K. Lauenroth. 1988. The effects of disturbance size and frequency on a shortgrass plant community. Ecology 69:1609-1617.

Coffin, D. P., and W. K. Lauenroth. 1989. Disturbances and gap dynamics in a semiarid grassland: a landscape-level approach. Landscape Ecology 3:19-27.

Collins, S. L. 1989. Experimental analysis of patch dynamics and community heterogeneity in tallgrass prairie. Vegetatio 85:57-66.

Collins, S. L., and S. M. Glenn. 1991. Importance of spatial and temporal dynamics in species regional abundance and distribution. Ecology 72:654-664.

Cood, R. E., and E. E. Lyons. 1983. The biology of Viola fimbriatula in a natural disturbance. Ecology 64:654-660.

Denslow, J. S. 1980. Gap partitioning among tropical rainforest trees. Biotropica 12:47-55.

De Steven, D. 1991. Experiments on mechanisms of tree establishment in old-field succession: seedling survival and growth. Ecology 72:1076-1088.

Duralia, T. E., and R. J. Reader. 1993. Does abundance reflect competitive ability?: a field test with three prairie grasses. Oikos 68:82-90.

Gibson, D. J. 1989. Effects of animal disturbance on tallgrass prairie vegetation. American Midland Naturalist 121:144154.

Gill, D. S., and P. L. Marks. 1991. Tree and shrub seedling colonization of old fields in central New York, USA. Ecological Monographs 61:183-206.

Goldberg, D. E. 1990. Components of resource competition in plant communities. Pages 357-364 in J. Grace and D. Tilman, editors. Perspectives on plant competition. Academic Press, San Diego, California, USA.

Goldberg, D. E. 1996. Competitive ability: definitions, contingency and correlated traits. Philosophical Transactions of the Royal Society of London B 351:1377-1385.

Goldberg, D. E., and A. Novoplansky. 1997. On the relative importance of competition in unproductive environments. Journal of Ecology 85:409-418.

Goldberg, D. E., R. Turkington, and L. Olsvig Whittaker. 
1995. Quantifying the community-level consequences of competition. Folia Geobotanica et Phytotaxonomica 30: 231-242.

Goldberg, D. E., and P. A. Werner. 1983. Equivalence of competitors in plant communities: a null hypothesis and a field experimental approach. American Journal of Botany 70:1098-1104.

Grime, J. P. 1979. Plant strategies and vegetation processes. John Wiley and Sons, Chichester, UK.

Harper, J. L. 1977. Population biology of plants. Academic Press, London, UK.

Hedges, L. V., J. Gurevitch, and P. S. Curtis. 1999. The metaanalysis of response ratios in experimental ecology. Ecology 80:1150-1156.

Hetrick, B. A. D., G. W. T. Wilson, and R. C. Schwab. 1994. Mycorrhizal activity in warm- and cool-season grasses: variation in nutrient-uptake strategies. Canadian Journal of Botany 72:1002-1008.

Hobbs, R. J., and L. Atkins. 1988. Effect of disturbance and nutrient addition on native and introduced annuals in plant communities in the Western Australian wheatbelt. Australian Journal of Ecology 13:171-179.

Hobbs, R. J., and V. J. Hobbs. 1987. Gophers and grassland: a model of vegetation response to patchy soil disturbance. Vegetatio 69:141-146.

Hobbs, R. J., and H. A. Mooney. 1985. Community and population dynamics of serpentine grassland annuals in relation to gopher disturbance. Oecologia 67:342-351.

Hobbs, R. J., and H. A. Mooney. 1991. Effects of rainfall variability and gopher disturbance on serpentine annual grassland dynamics. Ecology 72:59-68.

Hobbs, R. J., and D. A. Norton. 1996. Towards a conceptual framework for restoration ecology. Restoration Ecology 4: 93-110.

Horn, H. S., and R. H. MacArthur. 1972. Competition among fugitive species in a harlequin environment. Ecology 53: 749-752.

Jacquard, P. 1968. Manifestation et nature des relations sociales chez les végétaux supérieurs. Oecologia Plantarum 3:137-168.

Kupfer, J. A., and J. R. Runkle. 1996. Early gap successional pathways in a Fagus-Acer forest preserve: pattern and determinants. Journal of Vegetation Science 7:247-256.

Lambert, H., and H. Poorter. 1992. Inherent variation in growth rate between higher plants: a search for physiological causes and ecological consequences. Advances in Ecological Research 23:187-261.

Levins, R., and D. Culver. 1971. Regional coexistence of species and competition between rare species. Proceedings of the National Academy of Sciences (USA) 68:12461248 .

Martinsen, G. D., J. H. Cushman, and T. G. Whitman. 1990. Impact of pocket gopher disturbance on plant species diversity in a shortgrass prairie community. Oecologia 83: 132-138.

McClure, J. W., and T. D. Lee. 1993. Small-scale disturbance in a northern hardwoods forest: effects on tree species abundance and distribution. Canadian Journal of Forest Research 23:1347-1360.

McConnaughay, K. D. M., and F. A. Bazzaz. 1990. Interactions among colonizing annuals: is there an effect of gap size. Ecology 71:1941-1951.

McIntyre, S., and S. Lavorel. 1994. How environmental and disturbance factors influence species composition in temperate Australian grasslands. Journal of Vegetation Science 5:373-384.

McIntyre, S., S. Lavorel, and R. M. Tremont. 1995. Plant life-history attributes: their relationship to disturbance response in herbaceous vegetation. Journal of Ecology 83: $31-44$.
McPeek, M. A., and B. L. Peckarsky. 1998. Life histories and the strengths of species interactions: combining mortality, growth, and fecundity effects. Ecology 79:867-879.

Miao, S. L., and F. A. Bazzaz. 1990. Responses to nutrient pulses of two colonizers requiring different disturbance frequencies. Ecology 71:2166-2178.

Nakashizuka, T. 1989. Role of uprooting in composition and dynamics of an old-growth forest in Japan. Ecology 70: 1273-1278.

Pacala, S. W., C. D. Canham, J. Saponara, J. A. Silander, R. K. Kobe, and E. Ribbens. 1996. Forest models defined by field measurements: estimation, error analysis, and dynamics. Ecological Monographs 66:1-43.

Peart, D. R., and T. C. Foin. 1985. Analysis and prediction of population and community change: a grassland case study. Pages 315-339 in J. White, editor. Population structure of vegetation. Dr. W. Junk, Dordrecht, The Netherlands.

Peltzer, D. A., S. D. Wilson, and A. K. Gerry. 1998. Competition intensity along a productivity gradient in a lowdiversity grassland. American Naturalist 151:465-476.

Petraitis, P. S., R. E. Latham, and R. A. Niesenbaum. 1989. The maintenance of species diversity by disturbance. Quarterly Review of Biology 64:393-418.

Pickett, S. T. A., J. Kolasa, J. J. Armesto, and S. L. Collins. 1989. The ecological concept of disturbance and its expression at various hierarchical levels. Oikos 54:129-136.

Pickett, S. T. A., and P. S. White. 1985. The ecology of natural disturbance and patch dynamics. Academic Press, Orlando, Florida, USA.

Platt, W. J., and I. M. Weis. 1977. Resource partitioning within a guild of fugitive prairie plants. American Naturalist 111:479-513.

Platt, W. J., and I. M. Weis. 1985. An experimental study of competition among fugitive prairie plants. Ecology 66: 708-720.

Rabinowitz, D., and J. K. Rapp. 1985a. Colonization and establishment of Missouri prairie plants on artificial soil disturbances. II. Detecting small-scale plant-to-plant interactions and separating disturbance from resource provision. American Journal of Botany 72:1629-1634.

Rabinowitz, D., and J. K. Rapp. 1985b. Colonization and establishment of Missouri prairie plants on artificial soil disturbances. III. Species abundance distributions, survivorship, and rarity. American Journal of Botany 72:16351640.

Rabinowitz, D., J. K. Rapp, and P. M. Dixon. 1984. Competitive abilities of sparse grass species: means of persistence or cause of abundance. Ecology 65:1144-1154.

Ramey, R. E., and K. R. Troutman. 1976. Ohio prairies and the Ohio prairie survey project. Pages 207-210 in Proceedings of the Fifth Midwest Prairie Conference (22-24 August 1976, Iowa State University, Ames, Iowa, USA).

Schramm, P. 1978. The "do's" and "don'ts" of prairie restoration. Pages 139-150 in D. C. Glenn-Lewin and R. C. Landers, editors. Proceedings of the Fifth Midwest Prairie Conference, Iowa State University, Ames, Iowa, USA.

Smith, T., and M. Huston. 1989. A theory of the spatial and temporal dynamics of plant communities. Vegetatio 83:4970.

Sokal, R. R., and F. J. Rohlf. 1995. Biometry: the principles and practice of statistics in biological research. Third edition. Freeman, New York, New York, USA.

Suding, K. N. 1999. Processes responsible for changes in plant species abundance following disturbance. Dissertation. University of Michigan, Ann Arbor, Michigan, USA.

Sullivan, J. H., and K. M. Peterson. 1994. The importance of seedling competition in the segregation of spruce and fir in the southern Appalachians. New Forests 8:105-121. Tilman, D. 1988. Plant strategies and the dynamics and struc- 
ture of plant communities. Princeton University Press, Princeton, New Jersey, USA.

Tilman, D. 1994. Competition and biodiversity in spatially structured habitats. Ecology 75:2-16.

Tilman, D., and S. Pacala. 1993. The maintenance of species richness in plant communities. Pages 13-25 in R. E. Ricklefs and D. Schluter, editors. Species diversity in ecological communities: historical and geographical perspectives. University of Chicago Press, Chicago, Illinois, USA.

Tilman, D., and D. Wedin. 1991. Dynamics of nitrogen competition between successional grasses. Ecology 72:10381049.

Turkington, R., E. Klein, and C. P. Chanway. 1993. Interactive effects of nutrients and disturbance: an experimental test of plant strategy theory. Ecology 74:863-878.

Umbanhowar, C. E. 1992. Early patterns of revegetation on artificial earthen mounds in a northern mixed prairie. Canadian Journal of Botany 70:145-150.
Umbanhowar, C. E., Jr. 1995. Revegetation of earthen mounds along a topographic-productivity gradient in northern mixed prairie. Journal of Vegetation Science 6: 637-646.

Vitousek, P. M., and J. M. Melillo. 1979. Nitrate losses from disturbed forests: patterns and mechanisms. Forest Science 25:605-619.

Voss, E. G. 1972, 1985, 1996. Michigan flora, parts I-III. Cranbrook Institute of Science, Ann Arbor, Michigan, USA. Wilkinson, L. 1990. SYSTAT: the system for statistics. Version 5.05 for Windows. SYSTAT, Evanston, Illinois, USA. Wilson, S. D., and P. A. Keddy. 1986. Species competitive ability and position along a natural stress/disturbance gradient. Ecology 67:1236-1242.

Wilson, S. D., and J. M. Shay. 1990. Competition, fire and nutrients in a mixed-grass prairie. Ecology 71:1959-1967.

Wilson, S. D., and D. Tilman. 1995. Competitive response of eight old-field plant species in four environments. Ecology 71:1959-1967. 